\title{
¿PARA QUÉ SIRVEN LAS CAMPAÑAS ELECTORALES?: \\ LOS EFECTOS DE LA CAMPAÑA ELECTORAL ESPAÑOLA DE 1993*
}

\author{
María Fernández Mellizo-Soto \\ Instituto Juan March \\ E-mail: maria@ceacs.march.es
}

\begin{abstract}
RESUMEN
Este artículo explora los efectos de la campaña electoral española de 1993 en el comportamiento electoral siguiendo los antiguos presupuestos de Lazarsfeld y su grupo de Columbia, así como los de sus continuadores. Se ha contado para ello con una encuesta de datos de panel con mediciones antes y después de las elecciones. Se han perseguido dos grandes objetivos. En primer lugar, examinar mediante el modelo de activación si el voto (en el plano individual) está influido por la campaña electoral o si, en última instancia, queda "predeterminado» por las predisposiciones políticas antes de la campaña, y que se activan durante ella. En segundo lugar, analizar los efectos específicos de la campaña en el voto (los de activación, reforzamiento y conversión), así como la interpretación de los indecisos y de cómo fueron activadas sus predisposiciones hacia el PSOE. Este artículo muestra que los desarrollos de Lazarsfeld y su equipo son ciertos para el caso español: las predisposiciones políticas que los individuos presentan al comenzar la campaña electoral predicen con bastante precisión el voto que finalmente emiten. El efecto de la campaña electoral es, por lo tanto, reducido. Los efectos concretos que se produjeron en la campaña electoral de 1993 consistieron en el reforzamiento de quienes tenían unas preferencias de voto con-

* Agradezco los comentarios a una versión anterior de este artículo de José Ramón Montero, Modesto Escobar, Belén Barreiro y Marta Fraile, la ayuda estadística de Ignacio Sánchez-Cuenca y las facilidades del Instituto Juan March (CEACS), que han hecho posible que este trabajo se llevara a cabo. Una primera versión de este artículo fue presentada en el III Congreso Español de Ciencia Política y de la Administración, que tuvo lugar en Salamanca en septiembre de 1997. Mis agradecimientos son también para los participantes del grupo de trabajo «Elecciones y comportamiento electoral». Este artículo fue entregado a la REIS, para que se considerase su publicación, en febrero de 1999.
\end{abstract}


sistentes con las predisposiciones políticas y en la activación de los indecisos. Este último efecto fue el determinante de la victoria del PSOE sobre el PP, una victoria que no se recogía en buena parte de los sondeos realizados entonces.

La influencia de la campaña en el comportamiento electoral, tanto individual como agregado, es uno de los temas más apasionantes, así como menos desarrollados, de los estudios sobre el voto. Esta falta de desarrollo es sobre todo patente en Europa, y de una forma extrema en España. Este vacío es el que este estudio quiere cubrir.

La falta de rigor en el análisis de los efectos de la campaña en España hace que desde medios académicos, políticos o periodísticos se le atribuyan a la campaña efectos en el voto con poco conocimiento de su impacto real. Un ejemplo de interpretaciones académicas es la conclusión de Arango y Díez (1993: 10) respecto de las elecciones de 1993: «Las elecciones no habrán cumplido una mera función de notario de la expresión de la voluntad popular, sino que habrán constituido, además, un mecanismo esencial de la formación de la misma». En medios políticos, normalmente más tajantes en sus afirmaciones, también se encuentran ejemplos. Uno de ellos es la frase de Felipe González ante su electorado socialista la noche en que se confirmó su derrota electoral en 1996, dado que, contra todo pronóstico, el resultado final fue una leve victoria del PP sobre el PSOE. González señaló: «Nos ha faltado una semana [de campaña] o un debate [con Aznar]» (el énfasis es mío) ${ }^{1}$. Son también frecuentes las explicaciones de los mecanismos mediante los que actúa la campaña. En el artículo de Arango y Díez (1993: 14) se defiende la tesis de que uno de los factores que más influyeron en el resultado de 1993, en el que el PSOE ganó al PP pese a que las encuestas pronosticaban un empate o daban por ganador al segundo de estos partidos, fue la «movilización del electorado de izquierdas en dirección al PSOE — recuperación de parte del electorado socialista indeciso, freno de las pérdidas transferenciales hacia IU y captación de apoyos procedentes de la abstención, de los nuevos votantes e incluso de IU». En la literatura periodística se señalan similares argumentos. Sinova (1993: 137) apunta a que "(e)l PSOE tuvo la habilidad de movilizar a sus electores y obtuvo, contra todo pronóstico, casi un millón y medio de votos más que en la consulta anterior». Con los resultados de este trabajo empírico que aquí realizo defenderé argumentos similares, aunque espero que queden probados de forma más exhaustiva.

$Y$ es que el estudio de los efectos de la campaña electoral en el voto no es una tarea fácil. Desde el punto de vista empírico, requiere unos datos específicos, de panel, medidos en intervalos de tiempo de forma que se incluya el período de campaña. Desde el punto de vista teórico, la dificultad que presenta es que en realidad la campaña electoral no es sino un lapso de tiempo, y se manifiesta en elementos diversos, entre los que el más importante hoy en día

${ }^{1}$ El Pais, 4 de marzo de 1996, p. 24. 
son los medios de comunicación, en especial la televisión. En ese lapso de tiempo pueden confluir, además, otros factores que no necesariamente responden a la campaña electoral, pero cuyos efectos indefectiblemente interactúan con los de la propia campaña ${ }^{2}$.

Lazarsfeld y sus colaboradores de la Universidad de Columbia analizaron en los años cuarenta y cincuenta los efectos de la campaña en el comportamiento electoral, estudiando a los mismos individuos antes y después de la campaña. La obra más importante es la que realizaron Paul F. Lazarsfeld, Bernard Berelson y Hazel Gaudet en 1944, titulada The People's Choice. La parte más importante de esta obra para este trabajo es la que se centra en los tipos de efectos de la campaña electoral, el de activación, reforzamiento y conversión ${ }^{3}$. El proceso más importante que se produce en la campaña electoral es el de activación. El principal argumento que defienden estos autores en este sentido se puede resumir en las siguientes citas: «Lo que hace la campaña es activar sus [las de los votantes] predisposiciones políticas» (Lazarsfeld et al., 1944: 73); «Lo que hizo la campaña, digamos, no fue formar nuevas opiniones sino elevar viejas opiniones por encima del umbral de la consciencia y la decisión. Las campañas políticas son importantes principalmente porque activan predisposiciones latentes» (p. 74); «Hacer campaña para pedir el voto no es escribir sobre una tabula rasa; es mostrar a los hombres y mujeres que sus votos son normales y lógicos así como una expresión más o menos inevitable de tendencias con las que uno ya se ha alineado" (pp. 83-84). Por predisposiciones políticas estos autores entienden un conjunto de variables sociológicas como son el nivel económico, la religión y el lugar de residencia. La elección de estas variables como indicador de la inclinación política está determinada, en primer lugar, por el enfoque sociológico del comportamiento electoral al que estos autores están adscritos y, en segundo lugar, por tener como referente empírico Estados Unidos. El proceso de activación se produce, por lo tanto, cuando la tendencia política latente se manifiesta en el voto a esa tendencia.

El proceso de reforzamiento de la intención de voto que uno tiene antes de la campaña es cuantitativamente el efecto más importante de la campaña electoral. Como señalan estos autores: «Por lo tanto por lo que respecta al número de votantes, la propaganda de la campaña resulta no tanto en la ganancia de nuevos adherentes como en la prevención de la pérdida de los votantes ya inclinados favorablemente» (Lazarsfeld et al., 1944: 88). El proceso de conversión es un efecto mínimo de la campaña electoral, pero existente. Preguntándose por este fenómeno, Lazarsfeld et al. señalan: «¿Fue en realidad la gente convencida por la propagada de la campaña de renunciar a su decisión original para favorecer a la oposición o de decidir el voto de forma contraria a la que

2 Ejemplos de esto pueden ser el ataque al corazón que sufrió Julio Anguita en plena campaña electoral de 1993, o la devaluación de la peseta que se tuvo que realizar también en ese momento.

${ }^{3}$ Ver los capítulos VIII a XI, pp. 73-104. 
normalmente se asocia a sus características sociales [predisposiciones políticas]?»(1944: 94).

Recientemente se han realizado dos estudios que intentan poner a prueba la teoría desarrollada por el grupo de Columbia. Fundamentalmente pretenden incluir las predisposiciones políticas en los simples análisis de comparación entre la intención de voto y el voto a los que la teoría expuesta por este grupo había quedado reducida. Su mayor contribución a los estudios comenzados por Lazarsfeld et al. es la creación de un modelo de activación de la predisposición política, de acuerdo con los desarrollos teóricos y estadísticos de los estudios de comportamiento electoral y con las particularidades de cada país ${ }^{4}$ El primero de estos estudios fue desarrollado en Estados Unidos por Steven E. Finkel (1993) y el segundo en Alemania por el mismo autor y por Peter R. Schrott (1995). Estos estudios, desde mi punto de vista, superan parte de las críticas que se le han realizado a la teoría clásica. Este trabajo, en el que se analiza la campaña electoral española de 1993, se enmarca en esta tradición.

En este artículo se han perseguido dos grandes objetivos. En primer lugar, examinar mediante el modelo de activación si el voto (en el plano individual) está influido por la campaña electoral o si, en última instancia, éste queda "predeterminado" por las predisposiciones políticas antes de la campaña, que se activan durante ésta. En segundo lugar, analizar los efectos específicos de la campaña en el voto, el de activación, reforzamiento y conversión, así como la interpretación de los indecisos y de cómo fueron activadas sus predisposiciones hacia el PSOE5.

Por lo tanto, el primer apartado describirá las elecciones de 1993 en España, las variables del modelo de activación, las hipótesis del trabajo, los datos analizados y la forma en que se han operacionalizado las variables; el segundo apartado presentará los resultados del modelo de activación, para ver la influencia de la campaña en el comportamiento electoral (y para obtener el grado de predisposición política de cada individuo); en el tercer apartado se expondrán los efectos de activación, reforzamiento y conversión de la campaña de 1993; por último, el cuarto apartado investigará el fenómeno de la indecisión antes de la campaña electoral y su importancia en las elecciones de 1993.

${ }^{4}$ En cierta medida corroboran la teoría de Lazarsfeld, aunque los resultados no son del todo similares. Además, estos estudios difieren, aunque mínimamente, entre sí, tanto desde el punto vista de ciertos análisis que realizan como de los resultados a los que llegan. Cuando vaya realizando mis análisis y comentando los resultados a los que he llegado iré poniendo en relación, con sus similitudes y diferencias, a todos estos estudios.

5 En este trabajo no se analiza el perfil o las características de los indecisos del PSOE para esta campaña, tal y como han hecho Barreiro y Sánchez-Cuenca (1998). 


\section{LAS ELECCIONES DE 1993 EN ESPAÑA: UN MODELO DE ACTIVACIÓN POLÍTICA}

El estudio de los efectos de la campaña de las elecciones generales de 1993 en el comportamiento electoral puede realizarse para el caso español por los siguientes motivos. Primero, ya en el estudio alemán se argumentó la validez de la extrapolación del estudio de la activación en las elecciones presidenciales americanas a las elecciones generales alemanas, teniendo en cuenta que las variables del modelo de activación pueden variar dependiendo del tipo de elección y del país en cuestión. Lo que sí que es importante es que en las elecciones que se analicen la campaña goce de desarrollo o tradición, expansión o divulgación e intensidad (Finkel y Schrott, 1995: 351-352). En las elecciones del 93 en España se cuenta ya con un desarrollo o tradición importante de la campaña electoral. Desde las primeras elecciones en 1977, al terminar el régimen franquista, las elecciones de 1993 son las sextas (generales) que se realizan, con lo que se cuenta con una experiencia y unos medios considerables y comparables a los anteriores países. Hoy en día son los medios de comunicación los que fundamentalmente mediatizan las campañas electorales. Según un estudio reciente (del CIRES, en 1994), el 98 por 100 de los españoles poseen una televisión en color en casa y el 93 por 100 alguna radio ${ }^{6}$. Siendo éstos dos de los medios de comunicación más importantes para la divulgación y expansión de la campaña electoral, parece que en las elecciones de 1993 en España sí que se cumplen estos requisitos. Por último, estas elecciones son de especial intensidad, ya que es la primera vez desde que el PSOE llegó al poder que un partido de la oposición, el PP, le amenaza con igualarle, e incluso ganarle, pero desde luego no permitirle disfrutar de la mayoría absoluta que poseía desde hacía once años. Como señalan Arango y Díez (1993: 13): «El escenario electoral aparecía así abierto, dominado por la incertidumbre del resultado y la noción de una práctica igualdad de posibilidades entre PSOE y PP, y, por ello mismo, sometido a una fuerte tendencia a la polarización». Más adelante añaden (p. 16): «La convocatoria electoral supuso una modificación perceptiva del escenario electoral, al transformarse éste en una competición entre PSOE y PP en la que lo que estaba en juego era nada menos que el poder». Los casos de corrupción del gobierno y las divisiones internas dentro del partido socialista, muchas veces entre partido y gobierno, entre otras cosas, contribuyeron a este alto grado de competencia electoral.

Segundo, al igual que en el caso alemán, es interesante el estudio del modelo de activación de las disposiciones políticas, ya que esto quizá pueda explicar que las encuestas previas a la campaña, y también durante la campaña, predijeran una victoria del PP o, en todo caso, un empate entre esta fuerza y el

${ }^{6}$ Ver Díez Nicolás y Semetko (1995: 249). La frecuencia con la que se exponen a estos medios es muy alta, sobre todo en el caso de la televisión (el 90 por 100 de los españoles la ve todos los días). Un 63 por 100 escucha la radio todos los días. 
PSOE, y que el resultado mostrara la holgada victoria del partido socialista con respecto a los populares (aunque los socialistas no lograran la mayoría absoluta). Los procesos de activación y/o conversión son los que pueden ser claves a la hora de explicar esta situación, que no se predijo. Como señalan Arango y Díez (1993: 12-13), desde 1982 era la primera vez que circulaba la noción, a través de sondeos electorales, de que los resultados de los comicios se presentaban inciertos. Muestran unos datos de sondeos electorales del CIS que en marzo sitúan el voto al PP 1,3 puntos por encima del PSOE, 1 punto por encima en abril e igualados a principios de mayo, antes de empezar la campaña electoral. Lo cierto es que justo cuando empezó la campaña electoral y durante la misma la situación era de incertidumbre, prediciendo un empate, o la victoria de cada uno de los partidos. Lo que más sorprendió, sin embargo, no fue la victoria del PSOE, que estaba dentro de algunas predicciones, sino la gran diferencia, en relación a las predicciones que se habían hecho, entre estos dos partidos. Tercero, los datos de la encuesta ${ }^{7}$ con la que se ha trabajado se adaptan muy bien al tipo de estudio que se quiere realizar, ya que son datos de panel medidos en dos momentos del tiempo, antes de la campaña electoral y después de la misma ${ }^{8}$.

Por lo tanto, las del 93 son unas elecciones muy adecuadas para el análisis del efecto de la campaña en el comportamiento electoral. Cabría pensar que la campaña tuvo efectos, pero ¿es esto cierto?, ¿qué efectos tuvo?, ¿para qué sirvió?

Recordemos que la activación en general se refiere al hecho de votar, en la jerga de Lazarsfeld et al., a lo que se está predispuesto políticamente9. Con un modelo de activación se pretende ver si en última instancia las predisposiciones políticas antes de la campaña explican el voto o, por el contrario, su cambio durante la campaña tiene alguna importancia. Para ello, tanto en el caso estadounidense como en el alemán se han propuesto diferentes modelos, basados en consideraciones teóricas así como empíricas de cada uno de los países a los que hacen referencia. En este trabajo estos modelos se han tomado como guía, aunque adaptándolos al caso español. Ambos estudios toman la identificación partidista como orientación política a largo plazo, aunque el alemán añade a esta categoría el autoposicionamiento ideológico en una escala de izquierda a derecha. Estas dos variables han sido adoptadas en el caso español, donde sobre todo la ideología es una variable que se ha probado muy importante en

La encuesta es la española de la serie de las CNEP (Comparative National Election Study Proyect), dirigida por Richard Gunther y José Ramón Montero, y realizada por DATA a una muestra de 1.448 individuos, con una tasa de mortalidad del 5,11 por 100 .

${ }^{8}$ Más específicamente, la encuesta preelectoral fue realizada entre el 1 de mayo y el 21 del mismo mes, fecha en la que empezó oficialmente la campaña; la encuesta poselectoral se realizó desde el 12 de junio, seis días después de las elecciones ( 6 de junio), y hasta el 30 de julio. En la encuesta preelectoral se preguntó por la intención de voto en ese momento, y en la poselectoral por el voto emitido en los comicios.

9 Lazarsfeld et al. señalan este efecto sobre todo en los indecisos antes de la campaña. 
la determinación del comportamiento electora ${ }^{10}$. La identificación partidista presenta algunos problemas teóricos, de separación entre este concepto y el voto, y empíricos para el caso de España, esto es, dudas sobre su influencia en el voto ${ }^{11}$. Teóricamente, me parece que esta variable puede ser diferente al voto, y reflejar una predisposición a largo plazo. Empíricamente, con datos cruzados no se puede demostrar la escasa influencia de una variable en el voto, y con la comparación de datos agregados en el tiempo que no son de panel las extrapolaciones son erróneas. Por estas razones, me ha parecido conveniente introducirla en el modelo de activación, aparte de por consideraciones de comparación con los estudios anteriores. Entre las predisposiciones políticas a largo plazo el trabajo estadounidense incluye la raza. En el modelo español he incluido, sin embargo, la educación, variable de las socioeconómicas que se ha manifestado más potente en la determinación del voto en España ${ }^{12}$.

Los trabajos americano y alemán utilizan dos variables retrospectivas en el modelo de activación: la satisfacción con el estado de la economía y la valoración de la actuación del gobierno. Su inclusión responde a la creciente importancia que éstas están adoptando en los estudios sobre el comportamiento electoral en general, y en particular en estos dos países. En España también se ha subrayado su importancia, sobre todo en lo que concierne a la valoración de la economía (Lancaster y Lewis-Beck, 1986) ${ }^{13}$. Por ello, y por comparación con los estudios previos, he incluido estas variables en mi análisis ${ }^{14}$. La última

${ }^{10}$ Véase Lancaster y Lewis-Beck (1986) para la importancia de la ideología en España en las elecciones de 1982. Para las elecciones de 1993, Montero y Gunther (1994) señalan la importancia creciente de la ideología como explicación del comportamiento electoral español.

${ }_{11}$ Para la discusión sobre la importancia de la identificación con el partido en España, ver Del Castillo (1990). El problema más importante que presenta esta variable es, sin embargo, que son relativamente escasos los identificados con un partido en este país, por lo que presenta dificultades operativas (sobre todo por el escaso número de los muy identificados). Ver al respecto Schmitt y Holmberg (1995) y Biorcio y Mannheimer (1995).

${ }_{12}$ Su inclusión está basada en estudios como el de González (1993) o Lancaster y Lewis-Beck (1986) para las elecciones de 1982 en España, en los que se prueba, de una manera descriptiva en el primer caso y explicativa en el segundo, la influencia de factores relacionados con la clase en el voto. Variables como la clase social subjetiva o los ingresos no resultaron tan potentes como la educación; por lo tanto, decidí incluir esta última solamente. Un buen debate sobre la importancia, de la clase en el comportamiento electoral, y una defensa sobre la importancia tanto de variables relacionadas con la clase como de variables más políticas, se encuentra en González Álvarez (1998). En un principio, también decidí incluir la religiosidad, basada en el estudio citado de Lancaster y Lewis-Beck y en Montero (1993), que realiza un estudio descriptivo de la religiosidad y el voto en España hasta las elecciones de 1993 y demuestra por lo menos su importancia. Sin embargo, en mis análisis esta variable no resultó significativa, con lo cual no la incluí en el modelo.

${ }_{13}$ Maravall y Przeworski (1998) matizan la influencia de la valoración de la economía en el comportamiento electoral español. Estos autores llegan a la conclusión de que las reacciones políticas a la economía pueden estar mediadas por lealtades y por la ideología.

${ }_{14}$ Aunque, como luego se pondrá de manifiesto, ambas no resultan significativas en las regresiones realizadas, como ocurre en el caso alemán y para la economía en el caso estadounidense, por lo que son excluidas de los posteriores análisis. Sin embargo, me ha parecido interesante incluirlas al principio para seguir fielmente a los anteriores autores y por razones teóricas y empíricas para el caso español que avalan esta hipótesis. 
variable incluida en el modelo de activación, y que también incluyen los dos estudios previos, es la valoración de los candidatos políticos, más específicamente la diferencia de valoraciones. El liderazgo es una variable importante también en el caso español, según muestran algunos estudios ${ }^{15}$.

El modelo de activación tiene en cuenta estas variables antes de la campaña, en mayo, cuando la encuesta preelectoral fue realizada, y su variación en el período en el que ésta transcurre, entre mayo y julio, cuando fue realizada la encuesta poselectoral, para así determinar si el voto es en última instancia predicho por las variables antes de la campaña o su cambio durante ésta influye en el comportamiento electoral. Por esto el modelo también incluye el cambio que se produce en estas variables ${ }^{16}$. El cambio en la valoración de los candidatos, o su diferencia, es lo que se supone más sujeto a cambio durante la campaña, ya que es un factor a corto plazo en el que normalmente se intenta influir. Así, el modelo de activación propuesto para el caso español es el siguiente ${ }^{17}$ :

$$
\begin{aligned}
V O T O= & b_{0}+b_{1} \cdot I D P+b_{2} \cdot I D E O+b_{3} \cdot E C O N+b_{4} A C T G U B+b_{5^{*}} C A N D+b_{6} \cdot E D U+ \\
& +b_{7} \cdot C a m b i o I D P+b_{8^{*}} \text { CambioIDEO+b. }
\end{aligned}
$$

Donde:

VOTO = voto declarado, julio de 1993;

IDP = identificación con el partido, mayo de 1993;

IDEO = autoubicación ideológica en la escala izquierda-derecha, mayo de 1993;

ECON = satisfacción con el estado de la economía, mayo de 1993;

$A C T G U B=$ valoración de la actuación del gobierno, mayo de 1993;

CAND = diferencia en la valoración de los candidatos a la presidencia del gobierno, mayo de 1993;

EDU = educación declarada, mayo de 1993;

CambioIDP = cambio en la identificación partidista, mayo-julio de 1993;

CambioIDEO = cambio en el autoposicionamiento ideológico en la escala izquierda-derecha, mayo-julio de 1993;

CambioCAND = cambio en la valoración de los candidatos, en la diferencia de la valoración, mayo-julio de 1993;

$b_{0} \quad=$ constante;

$e \quad=$ término aleatorio del error;

$b_{1} a b_{9} \quad=$ coeficientes de la regresión que ligan cada variable al voto.

15 Ver Justel (1992) para este argumento, aun a pesar de las limitaciones estadísticas de sus análisis.

${ }^{16}$ La educación, como variable socioeconómica, no se la considera sujeta a cambio; lo son sólo las variables de actitudes, el resto. No se ha podido incluir el cambio en las variables de satisfacción con el estado de la economía y valoración de la actuación del gobierno debido a que no hay preguntas formuladas que representen a estas variables en la encuesta poselectoral con la que he trabajado.

${ }_{17}$ Más adelante se describirá la operacionalización de las variables. 
En general, las hipótesis que se han querido contrastar en este trabajo son las siguientes (Finkel, 1993; Finkel y Schrott, 1995: 357-360). Primera, las actitudes políticas antes de la campaña en última instancia deberían predecir el voto. Segunda, los cambios en estas actitudes políticas durante la campaña deberían reforzar las predicciones del voto antes de la campaña y dejar que pocos votantes voten de forma diferente de la predicha, esto es, sin cambios durante la campaña. Tercera, los individuos cuya intención de voto (preferencias) y predisposiciones políticas antes de la campaña son consistentes deberían votar en mayor medida en el sentido de sus preferencias, mientras que aquellos cuyas preferencias y predisposiciones son incongruentes deberían votar en mayor medida contra las preferencias iniciales. Esto supone otra hipótesis de máxima predicción del voto basado en las predisposiciones políticas antes de la campaña. En esta hipótesis habría que añadir la obvia en este sentido de que los individuos que están indecisos tienden en mayor medida a votar consistentemente con las predisposiciones políticas. Las anteriores hipótesis son de carácter teórico y pueden ser aplicadas a los diferentes tipos de elecciones y países. La cuarta hipótesis que se propone en este trabajo hace referencia a la situación particular de las elecciones españolas de 1993. Uno de los argumentos utilizados en la explicación del triunfo del PSOE sobre el PP, contra todo pronóstico previo, es que el PSOE convenció a gran parte de los indecisos, sobre todo de "sus» indecisos. Este argumento se explica precisamente a través del modelo de activación de las predisposiciones políticas que aquí se ha expuesto y se defiende a lo largo de todo el trabajo. Por lo tanto, la hipótesis cuarta propone que sobre todo debería ser importante el efecto de activación de la campaña electoral, aquellos indecisos que votan consistentemente, y ser este efecto mayor para los que votan al PSOE que para los que votan al PP.

La operacionalización de las variables del modelo de activación es la siguiente, dadas las preguntas disponibles en la encuesta utilizada. La variable dependiente del modelo de activación descrito es de tipo dicotómico y tiene por valor uno el voto al PSOE y por valor cero el voto al PP. El número total de casos es $816^{18}$. El resto de las variables del modelo se han operacionalizado de modo similar al de los estudios americano y alemán. En general, las variables están escaladas de forma que los valores positivos impliquen una actitud proPSOE y los negativos una actitud pro-PP, siendo el valor cero el punto neutro de la escala. Los valores missing han sido recodificados hacia el valor cero ${ }^{19}$. Así,

18 Se ha operacionalizado esta variable de esta forma (y no incluyendo otros partidos) fundamentalmente porque estos dos partidos son, sin duda y sobre todo desde 1989, los más importantes con diferencia en el panorama electoral español. Esto no es sólo desde un punto de vista cuantitativo; desde un punto de vista cualitativo, o subjetivo podríamos decir, el partido en el gobierno, el PSOE, tiene como principal oposición y competidor por el poder al otro partido, el PP. En las elecciones de 1993 es, además, como se ha señalado con anterioridad, cuando la sensación de competición bipartidista entre estos dos partidos es más fuerte en la escena política.

19 Aquí se está suponiendo la neutralidad de los individuos missing con respecto a sus actitudes pro-PSOE y pro-PP. 
la identificación partidista $(I D P)$ se ha medido sobre una escala de $-3 \mathrm{a}+3$, multiplicando la identificación de los individuos con el PSOE $(+1)$ o con el PP $(-1)$ por la fuerza declarada de esta identificación (de 1 para los poco identificados a 3 para los muy identificados). Aquellos que no estaban identificados ni con el PSOE ni con el PP fueron recodificados como missing. El cambio de identificación partidista (CambioIDP) en la campaña se ha medido sobre una escala que va de -6 a $+6^{20}$. La autoubicación ideológica $(I D E O)$ se ha medido sobre una escala de -5 (derecha) a +5 (izquierda). El cambio en la autoubicación ideológica (CambioIDEO) se ha medido sobre una escala de $-10 \mathrm{a}+10$. La valoración de la actuación gubernamental $(A C T G U B)$ se ha medido sobre una escala de -4 (mala) a +4 (buena) ${ }^{21}$. La satisfacción con el estado de la economía $(E C O N)$ se ha medido con una escala de -2 (mala) a +2 (buena). La diferencia en la valoración de los candidatos $(C A N D)$ es una variable escalada de -10 (prefiere Aznar a Felipe) a +10 (prefiere Felipe a Aznar) ${ }^{22}$. El cambio de la valoración de los candidatos durante la campaña, o de la diferencia en la valoración de los candidatos, es una variable que se ha medido con una escala de -20 a +20 . La educación $(E D U)$ se ha medido sobre una escala de -4 (poca) $a+4$ (mucha).

En los apartados que siguen se va a contrastar el modelo de activación política con los datos de la encuesta para analizar el efecto global de la campaña sobre el voto (si la campaña influye el voto o éste está determinado por las predisposiciones políticas antes de la campaña y que se activan durante ésta), para luego pasar a explorar la naturaleza de esos efectos (si son de activación, reforzamiento o conversión) y finalizar con el análisis de la activación de los indecisos que finalmente votaron al PSOE.

\section{EFECTOS GLOBALES DE LA CAMPAÑA: EL CONTRASTE DEL MODELO DE ACTIVACIÓN POLÍTICA}

La técnica estadística utilizada para la estimación del modelo de activación de las disposiciones políticas en el caso español es la regresión logística, que estimo la más adecuada para el tratamiento de variables dependientes dicotómicas ${ }^{23}$.

${ }^{20}$ La lógica de estas variables de cambio es parecida. Los valores positivos implican cambio pro-PSOE, y los negativos cambio pro-PP. Para valores absolutos altos los cambios son más fuertes, $y$ viceversa. El valor cero significa que no ha habido cambio.

${ }_{21}$ En realidad, se ha formado a partir de un índice en el que se pregunta por la actuación del gobierno en diferentes áreas.

${ }^{22}$ La valoración de cada uno de los candidatos se ha medido en una escala que va de -5 (mala) a +5 (buena). Los que no conocen al candidato se les ha considerado como missing.

${ }^{23}$ Esta elección hace que los resultados no puedan ser directamente comparables con los de Finkel (1993) para Estados Unidos y Finkel y Shcrott (1995) para Alemania, que utilizan la regresión por probabilidad lineal usando el procedimiento de mínimos cuadrados generalizados adecuado para tratar con variables dependientes dicotómicas. Se ha optado en este trabajo por la técnica de la regresión logística, ya que la que utilizan estos autores presenta muchos límites. 
En las tablas 1 y 2 se presentan los principales resultados obtenidos de contrastar el modelo de activación propuesto. En la primera tabla aparecen los resultados de la regresión con todas las variables del modelo, tanto en mayo, antes de la campaña, como su cambio entre mayo y julio, fecha posterior a la campaña electoral.

\section{TABLA 1}

Modelo de regresión logística completo para predecir el voto

\begin{tabular}{|c|c|c|c|c|c|}
\hline Variable & Media & $\begin{array}{l}\text { Desviación } \\
\text { típica }\end{array}$ & Coeficiente $\mathrm{b}^{\mathrm{b}}$ & $\begin{array}{c}\text { Error } \\
\text { estándar }\end{array}$ & $\begin{array}{c}\text { Valor } \\
z^{c}\end{array}$ \\
\hline $\begin{array}{l}\text { Identificación partidista antes de la cam- } \\
\text { paña }\end{array}$ & 0,1692 & 0,987 & $3,0262^{*}$ & 0,7116 & 4,252 \\
\hline Cambio en la identificación partidista .. & 0,0359 & 1,1035 & $2,1365^{*}$ & 0,4966 & 4,302 \\
\hline Ideología antes de la campaña ................ & 1,0228 & 2,4867 & $0,683^{*}$ & 0,1451 & 4,706 \\
\hline Cambio en la ideología .............................. & $-0,096$ & 2,0454 & $0,7617^{*}$ & 0,1479 & 5,151 \\
\hline $\begin{array}{l}\text { Valoración de la economía antes de la } \\
\text { campaña }\end{array}$ & $-0,7417$ & 0,8858 & - & - & - \\
\hline $\begin{array}{l}\text { Valoración de la actuación gubernamen- } \\
\text { tal antes de la campaña ........................... }\end{array}$ & $-0,1436$ & 2,3419 & - & - & - \\
\hline $\begin{array}{l}\text { Valoración de los candidatos antes de la } \\
\text { campaña }\end{array}$ & 1,5504 & 4,9145 & $0,6277^{*}$ & 0,091 & 6,892 \\
\hline $\begin{array}{l}\text { Cambio en la valoración de los candi- } \\
\text { datos }\end{array}$ & $-0,1146$ & 3,6389 & $0,5117^{*}$ & 0,088 & 5,812 \\
\hline 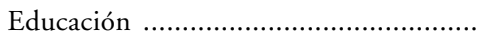 & 0,9682 & 1,835 & $0,2754^{*}$ & 0,1237 & 2,226 \\
\hline 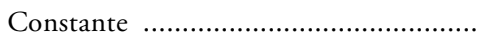 & - & & $-1,0164^{*}$ & 0,3301 & $-3,079$ \\
\hline
\end{tabular}

Número de casos $=816$.

Pseudo $\mathrm{R}^{2}=0,8651^{\mathrm{d}}$.

Porcentaje de casos correctamente predichos $=96,81^{\mathrm{e}}$.

NOTAS:

a La variable dependiente toma los siguientes valores: 1 si voto a PSOE, 0 si voto a PP.

b Un asterisco quiere decir que el coeficiente de la variable es significativo al 5 por 100 . Una raya significa que el coeficiente no es significativo (por ello no se ha incluido, así como su error estándar y su valor z; el resto de los resultados del modelo: coeficientes de las otras variables, pseudo $\mathrm{R}^{2}$, porcentaje de casos correctamente predichos, etc., han sido calculados sin su inclusión).

El valor z resulta de dividir cada coeficiente por el valor estándar de la estimación.

d Este valor se ha hallado de sumar los casos negativos correctamente predichos (311) más los casos positivos correctamente predichos (479) y dividir esta cifra por el total de casos (816). La sensibilidad del modelo es del 97,96 por 100 y la especificidad del 95,11 por 100 . El área por debajo de la curva ROC es 0,9941 .

e El modelo satisface el test de bondad de ajuste $\mathrm{Chi}^{2}\left(\mathrm{p}>\mathrm{chi}^{2}=0,1287\right.$; con los patrones de covarianza reducidos a 10 grupos) (ver el Apéndice para los detalles estadísticos). No parecen existir problemas de multicolinearidad, pues las correlaciones entre las variables son moderadas. Las únicas que sobrepasan el valor de 0,5 son entre la identificación partidista y la valoración de los candidatos antes de la campaña $(0,5156)$ y entre la ideología y la valoración de los candidatos antes de la campaña $(0,5462)$. 
Como puede observarse, la identificación partidista, la ideología, la diferencia en la valoración de los candidatos y la educación muestran un sesgo pro-PSOE al tener signo positivo, sobre todo la diferencia en la valoración de los candidatos y, aunque menos, la identificación partidista. Por el contrario, la satisfacción con la economía y la valoración de la actuación del gobierno muestran un sesgo pro-PP, al mostrar un signo negativo, sobre todo la variable de la economía ${ }^{24}$. Mientras que el cambio de identificación partidista tiene un sesgo hacia el PSOE, el cambio de ideología y de valoración de los candidatos lo tienen hacia el PP. Sin embargo, no sirve la mera descripción estadística de las variables para extraer conclusiones acerca de qué influye en el voto o si importan los cambios producidos en las variables durante la campaña para la determinación del mismo. Para comprobar la importancia relativa de estas variables en la explicación del voto observamos los valores $z$, aun siendo conscientes de los problemas derivados de comparar estos valores para cada una de las variables. Así, la diferencia de las valoraciones de los candidatos antes de la campaña es la variable que más explica el voto, seguida de su cambio durante ésta. El cambio de ideología durante la campaña y la ideología antes de la campaña son las siguientes dos variables que lo explican. Por último, encontramos el cambio de identificación partidista durante la campaña y su nivel antes de la campaña, así como, finalmente, la educación que se posee ${ }^{25}$.

De esta forma, parece que las variables de cambio durante la campaña pueden ser muy importantes para la determinación del voto. En los casos de la ideología y de la identificación partidista, los cambios que se producen durante la campaña sobrepasan el impacto de su nivel en mayo, concediendo potencialmente un peso muy importante al peso de la campaña en el voto. A un resultado parecido llegan los estudios realizados en Estados Unidos y Alemania (Finkel, 1993: 10; Finkel y Schrott, 1995: 363) ${ }^{26}$. En la tabla 2 se presenta el mismo modelo pero sin las variables de cambio durante la campaña ${ }^{27}$.

${ }^{24} \mathrm{La}$ variable de la actuación gubernamental muestra una desviación típica algo elevada en comparación con el resto (de 2,3419, y su rango de medida es 9), con lo cual la utilización de la media como medida resumen y de comparación está limitada.

${ }^{25}$ Las variables relativas a la satisfacción con el estado de la economía y a la valoración de la actuación gubernamental no salieron significativas, con lo que fueron posteriormente excluidas del análisis. También se utilizó una variable que mide la valoración general de la actuación del gobierno en vez del índice de actuación en varias materias que se había introducido inicialmente, que tampoco resultó significativa.

${ }^{26}$ La identificación partidista y su cambio durante la campaña no resultan en este trabajo unos predictores del voto tan potentes como en el caso de los otros dos estudios. Por el contrario, el papel tan importante de la diferencia en la valoración de los candidatos y su cambio durante la campaña en el voto que resulta en este trabajo no es hallado en los anteriores.

${ }^{27}$ Se han probado ambos modelos sin la identificación partidista, y en el caso del modelo completo sin su cambio durante la campaña. Esto se ha realizado para probar que las altas pseudo $\mathrm{R}^{2}$ que se obtienen tanto en el modelo completo $(0,8651)$ como en el que excluye los cambios durante la campaña $(0,5663)$ no responden a la inclusión de esta variable (para el primer caso, si se excluyen tanto la variable antes de la campaña como su cambio durante la misma, la pseudo $\mathrm{R}^{2}$ resulta de 0,8286 , un poco menor, y para el segundo caso, si se excluye su nivel antes de la campaña se obtiene uno de 0,5774 , incluso un poquito mayor). Por razones de comparación con los otros estudios se ha decidido mantener estas variables. 


\section{TABLA 2}

Modelo de regresión logística para predecir el voto antes de la campaña

\begin{tabular}{|c|c|c|c|c|c|}
\hline Variable & Media & $\begin{array}{l}\text { Desviación } \\
\text { tipica }\end{array}$ & Coeficiente ${ }^{\mathrm{b}}$ & $\begin{array}{l}\text { Error } \\
\text { estándar }\end{array}$ & $\begin{array}{c}\text { Valor } \\
z^{c}\end{array}$ \\
\hline Ideología & 1,0228 & 2,4867 & $0,343^{*}$ & 0,0604 & 5,676 \\
\hline Valoración de la economía ..................... & $-0,7417$ & 0,8858 & - & - & - \\
\hline $\begin{array}{l}\text { Valoración de la actuación gubernamen- } \\
\text { tal }\end{array}$ & $-0,1436$ & 2,3419 & - & - & - \\
\hline Valoración de los candidatos .................... & 1,5504 & 4,9145 & $0,3901^{*}$ & 0,0382 & 10,222 \\
\hline Educación & 0,9682 & 1,835 & $0,2811^{*}$ & 0,0692 & 4,062 \\
\hline Constante & - & & $-0,5343^{*}$ & 0,1555 & $-3,463$ \\
\hline
\end{tabular}

Número de casos $=816$.

Pseudo $\mathrm{R}^{2}=0,5863^{\mathrm{d}}$.

Porcentaje de casos correctamente predichos $=89,93^{\mathrm{e}}$.

NOTAS:

a Ver nota $a$ de tabla 1.

b Ver nota $b$ de tabla 1.

- Ver nota $c$ de tabla 1.

d Este porcentaje se ha hallado de sumar los casos negativos correctamente predichos (275) más los casos positivos correctamente predichos (454) y dividir esta cifra por el total de casos (816). La sensibilidad del modelo es del 92,84 por 100 y la especificidad del 84,10 por 100 . El área por debajo de la curva ROC es 0,9491 .

El modelo satisface el test de bondad de ajuste $\mathrm{Chi}^{2}\left(\mathrm{p}>\mathrm{chi}^{2}=0,6229\right.$; eliminando la observación 937, que presenta un residuo muy elevado) (ver el Apéndice para los detalles estadísticos). Ver nota $e$ de tabla 1 para la ausencia de multicolinearidad del modelo.

A partir de este modelo se ha generado un voto predicho para cada individuo con las variables relevantes de antes de la campaña ${ }^{28}$. Este modelo, o modelo de activación de predisposiciones políticas antes de la campaña, predice bien el 89,93 por 100 de los casos. Las variables antes de la campaña predicen correctamente, por lo tanto, un porcentaje muy alto de casos, sin necesidad de los cambios acontecidos durante la campaña. Con el modelo completo, con los cambios durante la campaña, de la tabla anterior, se predice correctamente el 96,81 por 100 de los casos. Por lo tanto, la inclusión de los cambios durante la campaña hace que el poder predictivo del modelo aumente en 6,88 puntos. El efecto de la inclusión de las variables de cambio durante la campaña supone un crecimiento pequeño en el poder predictivo del modelo de predicción del voto, aunque no despreciable. Esto es debido fundamentalmente a

${ }^{28}$ Este procedimiento lo que hace es generar una probabilidad predicha para cada individuo, y aquellos con puntuaciones más altas de 0,5 el modelo les predice votar al PSOE, y aquellos con puntuaciones por debajo de 0,5 les predice votar al PP. 
que en su ausencia la predicción se hace de una forma muy correcta ${ }^{29}$. Aun así, la hipótesis con la que partíamos al principio de que las actitudes políticas de antes de la campaña en última instancia predicen el voto queda ampliamente demostrada.

Para, por otra parte, comprobar si los cambios en las actitudes durante la campaña refuerzan las predicciones de estas variables antes de la campaña, la segunda hipótesis, hay que hacer un análisis diferente. Se han obtenido dos variables con las probabilidades de voto de ambos modelos, sin los cambios producidos en las actitudes durante la campaña, por una parte, y con estos cambios, por otra. La correlación entre ambas variables es 0,86 . Esta correlación es muy alta, lo que quiere decir que la mayoría de los que son predichos para votar a un partido en mayo, antes de la campaña, lo son también en julio, después de la campaña y con los cambios en las actitudes que ésta ha provocado ${ }^{30}$. El siguiente análisis clarifica este punto. Se presentan en la tabla 3 unos modelos de regresión lineal para predecir las actitudes políticas después de la campaña. Se quiere conocer si son las actitudes políticas antes de la campaña las que en última instancia explican sus valores de después de la campaña y si, además, éstas no están influidas por variables propias de la campaña electoral, como la exposición a la televisión o a los periódicos ${ }^{31}$. También se han utilizado dos variables de control, la educación y el interés en la política ${ }^{32}$. Mediante este análisis podemos ver si, aunque las variables de cambio en las actitudes durante la campaña tengan alguna importancia en el modelo (ver tabla 1), las variaciones de éstas durante la campaña van en el sentido predicho por las actitudes antes de la campaña.

Los resultados que arroja la tabla 3 son concluyentes. Al comparar los valores $t$ se observa claramente que las actitudes existentes antes de la campaña, sobre la valoración de los candidatos, la identificación partidista y la ideología, son las

29 Para el caso de Estados Unidos, el modelo en el que se excluyen los cambios producidos por la campaña electoral predice correctamente el 81 por 100 de los casos, mientras que el modelo completo el 84 por 100 (Finkel, 1993: 10). Para el caso alemán, sólo se muestra el porcentaje de casos correctamente predichos por las variables de antes de la campaña (83 por 100) (Finkel y Schrott, 1995: 363).

${ }^{30}$ Los estudios precedentes obtienen todavía unas correlaciones más altas, 0,92 en el caso de Estados Unidos (Finkel, 1993: 11) y 0,93 en el caso de Alemania (Finkel y Schrott, 1995: 365). Esto quiere decir que en el caso español la campaña produce un cambio de voto predicho mayor que en los otros casos, aunque, como en ellos, muy pequeño.

${ }^{31}$ La variable que mide la exposición a la televisión (TELE) está medida sobre una escala de 1 (poca) a 20 (mucha) y se ha formado mediante la multiplicación de la frecuencia con la que se ha seguido durante la campaña la información política a través de la televisión ( 5 si alta, 1 si baja) y el interés con que se ha seguido la información sobre las elecciones en la televisión (1 si poco, 4 si mucho). De forma similar se ha operacionalizado la exposición a los periódicos (PERIODI). Ver el análisis de los medios de comunicación para la misma campaña que aquí se analiza de Gunther, Montero y Wert (1999).

${ }^{32}$ La educación (EDUCACIÓN) se ha medido sobre una escala de 1 (poca) a 8 (mucha), siguiendo la misma pregunta de la encuesta que fue utilizada para la variable EDU de los modelos anteriores. Para el interés en la política (INTPOLI) se ha utilizado una variable escalada entre 1 (poco) y 4 (mucho). 


\section{TABLA 3}

\section{Modelos de regresión para predecir la valoración de los candidatos, la identificación partidista y la ideología después de la campaña}

\begin{tabular}{|c|c|c|c|c|c|c|}
\hline Variables & $\begin{array}{l}\text { Valoración } \\
\text { de los } \\
\text { candidatos } \\
\text { después } \\
\text { de la } \\
\text { campaña }\end{array}$ & Valor $t^{\mathrm{b}}$ & $\begin{array}{l}\text { Identifi- } \\
\text { cación } \\
\text { partidista } \\
\text { después } \\
\text { de la } \\
\text { campaña }\end{array}$ & Valor $t$ & $\begin{array}{l}\text { Ideología } \\
\text { después } \\
\text { de la } \\
\text { campaña }\end{array}$ & Valor $t$ \\
\hline $\begin{array}{l}\text { Valoración de los candidatos } \\
\text { antes de la campaña ......... }\end{array}$ & $\begin{array}{c}0,6068^{*} \\
(0,023)\end{array}$ & 26,299 & $\begin{array}{c}0,077^{*} \\
(0,0067)\end{array}$ & 11,557 & $\begin{array}{c}0,1196 \\
(0,0115)\end{array}$ & 10,353 \\
\hline $\begin{array}{l}\text { Identificación partidista antes } \\
\text { de la campaña }\end{array}$ & $\begin{array}{c}0,2713^{*} \\
(0,1044)\end{array}$ & 2,598 & $\begin{array}{r}0,3455^{*} \\
(0,0301)\end{array}$ & 11,457 & - & - \\
\hline $\begin{array}{c}\text { Ideología antes de la cam- } \\
\text { paña }\end{array}$ & $\begin{array}{c}0,2371^{*} \\
(0,0426)\end{array}$ & 5,562 & $\begin{array}{r}0,0589^{*} \\
(0,0123)\end{array}$ & 4,782 & $\begin{array}{r}0,5414^{*} \\
(0,0228)\end{array}$ & 23,706 \\
\hline Educación .......................... & $\begin{array}{c}-0,1917^{*} \\
(0,061)\end{array}$ & $-3,719$ & $\begin{array}{r}-0,0549^{*} \\
(0,0176)\end{array}$ & $-3,116$ & - & - \\
\hline Interés en la política ............ & - & - & - & - & - & - \\
\hline Exposición a la televisión .... & - & - & - & - & - & - \\
\hline Exposición al periódico ....... & - & - & - & - & - & - \\
\hline Constante .......................... & $\begin{array}{r}0,9252^{*} \\
(0,2488)\end{array}$ & 3,719 & $\begin{array}{c}0,173^{*} \\
(0,0718)\end{array}$ & 2,408 & $\begin{array}{c}0,1875^{*} \\
(0,0517)\end{array}$ & 3,628 \\
\hline $\mathrm{R}^{2}$ ajustado . & $0,5359^{c}$ & & $0,3722^{\mathrm{d}}$ & & $0,4796^{\mathrm{e}}$ & \\
\hline
\end{tabular}

Número de casos $=1.448$.

NOTAS:

a Ver nota $b$ de tabla 1. Entre paréntesis está el error estándar.

b El valor $t$ se halla al dividir el coeficiente entre el error estándar.

c La raíz del MSE es 3,2944 (la escala de la variable dependiente es de -10 a 10). El modelo satisface la prueba de la heteroscedasticidad $\mathrm{Chi}^{2}\left(\mathrm{p}>\mathrm{chi}^{2}=0,3387\right)$. El modelo no está bien especificado, la prueba de Ramsey es significativa $(\mathrm{p}>\mathrm{F}=0,0004)$. Sin embargo, debido al carácter de este análisis, no se considera oportuno investigar muy en profundidad para descubrir cuál es el fallo de especificación.

d La raíz del MSE es 0,9513 (la escala de la variable dependiente es de -3 a 3). El modelo satisface la prueba de la heteroscedasticidad $\mathrm{Chi}^{2}\left(\mathrm{p}>\mathrm{chi}^{2}=0,7997\right)$. El modelo está bien especificado, pues supera la prueba de Ramsey $(\mathrm{p}>\mathrm{F}=0,1738)$.

- La raíz del MSE es 1,8096 (la escala de la variable dependiente es de -5 a 5). El modelo no satisface la prueba de la heteroscedasticidad $\mathrm{Chi}^{2}\left(\mathrm{p}>\mathrm{chi}^{2}=0\right)$. El problema puede estar o bien en la variable dependiente, ya que el gráfico de los residuos contra los valores predichos por el modelo presenta una estructura decreciente, o bien en la variable independiente relativa a la ideología antes de la campaña, pues tanto el gráfico de los residuos contra los valores de esta variable como el de las desviaciones típicas de la variable dependiente contra los mismos valores presentan tendencias ligeramente decrecientes. A priori, parece más fuerte el primero de los problemas (ver el Apéndice para los detalles estadísticos). Sin embargo, no se considera necesario para los propósitos de este estudio repetir el análisis por mínimos cuadrados generalizados o ponderados. El modelo no está bien especificado pues la prueba de Ramsey falla $(\mathrm{p}>\mathrm{F}=0,0161)$ (ver nota $c)$. 
que explican en mayor medida las actitudes de después de la campaña. Esto es particularmente evidente en el caso de la valoración de los candidatos y la identificación partidista después de la campaña ${ }^{33}$. La ideología después de la campaña no viene, sin embargo, explicada por la identificación partidista antes de ésta, y lo es en mucha mayor medida por la ideología antes de la campaña que por la valoración de los candidatos también antes de la campaña. La prueba definitiva de la hipótesis de reforzamiento de los cambios durante la campaña es que tanto la exposición a la televisión como a los periódicos no son variables significativas para la explicación de las actitudes después de la campaña, con lo cual no parece que puedan explicar cambios en dirección contraria de las predicciones realizadas antes de la campaña ${ }^{34}$. Por lo tanto, la hipótesis de partida queda probada; los cambios de actitudes políticas durante la campaña, cuando se producen, actúan en el sentido predicho por las actitudes antes de la campaña ${ }^{35}$.

\section{EFECTOS DE ACTIVACIÓN, REFORZAMIENTO Y CONVERSIÓN DE LA CAMPAÑA DE 1993}

Para analizar los efectos específicos (de activación, reforzamiento y conversión) de la campaña electoral de 1993 en España es necesario incluir la intención de voto antes de la campaña. Hasta el momento, los análisis que he realizado sólo han tenido en cuenta las predisposiciones políticas antes de la campaña y el voto.

Tal y como se aprecia en la tabla 4, antes de la campaña hay mayor intención de voto al PSOE que al PP. Lo que sí es un elemento de incertidumbre es el gran grupo de indecisos antes de la campaña que pueden determinar el resultado final (casi un 16 por 100). Si tenemos en cuenta el voto declarado, vemos que el PSOE ha aumentado su apoyo en más de 10 puntos y el PP en menos de 6 puntos, con lo que la diferencia entre ambos partidos en el voto es todavía mayor. El PSOE logra en mayor medida que el PP que los que le apoyaban antes de la campaña le voten. Los indecisos antes de la campaña votan en mucha mayor medida al PSOE que al PP (un 63,39 por 100 de éstos votan al PSOE y el resto al PP) ${ }^{36}$.

${ }^{33}$ Nótese la fuerza predictiva de la variable de valoración de los candidatos antes de la campaña. Para el caso de la explicación de la identificación partidista después de la campaña, su valor $t$ es mayor, aunque por muy poco, que el de la identificación partidista antes de la misma.

${ }^{34} \mathrm{El}$ interés en la política tampoco es significativo en ninguna regresión. La educación lo es en la explicación de la diferencia en la valoración de los candidatos y la identificación partidista en julio, aunque su influencia es menor que las actitudes políticas antes de la campaña. Nótese que el sentido es siempre negativo, es decir, cuanto menos educación, más valoración de Felipe sobre Aznar, más identificación con el PSOE, y la ideología es más de izquierdas después de la campaña.

35 El estudio alemán en el que también se realiza este análisis arroja unos resultados muy similares a los aquí mostrados (ver Finkel y Schrott 1995: 366).

${ }^{36}$ Con respecto al caso alemán hay diferencias respecto a los resultados aquí mostrados (Finkel y Schrott, 1995: 368 y 370). Parece que el grupo más decisivo del caso español en comparación con el alemán es el de indecisos, que votan en mayor medida al PSOE. 
TABLA 4

Cruce del voto y la intención de voto al PSOE y al PP

\begin{tabular}{|c|c|c|c|c|}
\hline \multirow[b]{2}{*}{ Voto $(\%)^{\mathrm{a}}$} & \multicolumn{4}{|c|}{ Intención de voto antes de la campaña (\%) } \\
\hline & $P P$ & Indeciso & PSOE & Total \\
\hline 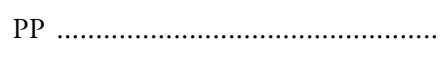 & $\begin{array}{l}94,85 \\
(221)\end{array}$ & $\begin{array}{r}36,61 \\
(41)\end{array}$ & $\begin{array}{l}3,33 \\
(12)\end{array}$ & $\begin{array}{l}38,87 \\
(274)\end{array}$ \\
\hline 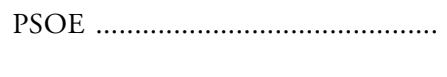 & $\begin{array}{l}5,15 \\
(12)\end{array}$ & $\begin{array}{r}63,39 \\
(71)\end{array}$ & $\begin{array}{l}96,67 \\
(348)\end{array}$ & $\begin{array}{l}61,13 \\
(431)\end{array}$ \\
\hline Porcentaje de todos los votantes ...... & $\begin{array}{l}33,05 \\
(233)\end{array}$ & $\begin{array}{l}15,89 \\
(112)\end{array}$ & $\begin{array}{l}51,06 \\
(360)\end{array}$ & $\begin{array}{c}100 \\
(705)\end{array}$ \\
\hline
\end{tabular}

NOTAS:

a El número de casos está entre paréntesis.

Pero falta incluir en este análisis de la intención de voto y del voto las predisposiciones políticas, que tan importantes resultan para ver los efectos de la campaña en el comportamiento electoral. Esto es lo que se va a realizar a continuación. La tercera hipótesis de este trabajo implica que quienes no cambian de preferencia en el voto durante la campaña suelen ser quienes tienen una intención de voto consistente con las predisposiciones políticas, y viceversa. Además, apunta que los indecisos deberían votar de acuerdo a sus predisposiciones iniciales. La tabla 5 es semejante a la que en los años cuarenta realizaran Lazarsfeld y su equipo, aunque para el caso español. La predisposición (política) es una variable que se ha formado con el voto predicho del modelo de activación (sin cambios de campaña) mostrado en la tabla 2. Esta variable es dicotómica. Adopta el valor uno si el individuo tiene una predisposición política hacia el PSOE y el valor cero si hacia el $\mathrm{PP}^{37}$. En la tabla 5 se cruzan la intención de voto antes de la campaña con el voto, pero según si éstos son consistentes o no con la predisposición política antes de la campaña.

Un 97 por 100 de los que tienen una intención de voto antes de la campaña consistente con las predisposiciones políticas votan en el mismo sentido, mientras que lo hacen un 74,07 por 100 de los que su intención de voto antes de la campaña es inconsistente con las disposiciones. Por otro lado, los indecisos votan en mayor medida consistentemente con las predisposiciones de antes de la campaña (un 81,25 por 100) que contra ellas (un $18,75$ por 100$)$. La hipótesis tres parece confirmada. Pero hay que profundizar más en los efectos de la campaña. El reforzamiento, o mantenimiento

${ }^{37}$ Si la probabilidad que le asigna el modelo de activación antes de la campaña es mayor que 0,5 se considera que tiene una predisposición política hacia el PSOE, y si es menor que 0,5 se considera que la predisposición es, sin embargo, hacia el PP. 


\section{TABLA 5}

Efectos de refuerzo, activación y conversión

\begin{tabular}{|c|c|c|}
\hline \multirow[b]{2}{*}{$\begin{array}{l}\text { Intención de voto antes } \\
\text { de la campaña }\end{array}$} & \multicolumn{2}{|c|}{$V t_{0}^{\mathrm{b}}$} \\
\hline & $\begin{array}{l}\text { Consistente con la disposición } \\
\text { de antes de la campaña }\end{array}$ & $\begin{array}{l}\text { Inconsistente con la disposición } \\
\text { de antes de la campaña }\end{array}$ \\
\hline Consistente con la disposición ........ & A. Refuerzo & D. Conversión \\
\hline 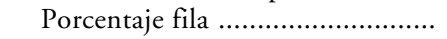 & 97 & 3 \\
\hline Porcentaje del total ....................... & 77,87 & 2,41 \\
\hline Número de casos .......................... & 549 & 17 \\
\hline Inconsistente con la disposición ..... & B. Reactivación & E. Refuerzo \\
\hline Porcentaje fila .............................. & 25,93 & 74,07 \\
\hline Porcentaje del total ........................ & 0,99 & 2,84 \\
\hline Númerode casos ........................... & 7 & 20 \\
\hline 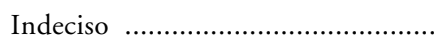 & C. Activación & F. Conversión \\
\hline Porcentaje fila ........................... & 81,25 & 18,75 \\
\hline Porcentaje del total ....................... & 12,91 & 2,98 \\
\hline 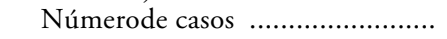 & 91 & 21 \\
\hline
\end{tabular}

NOTAS:

El número total de casos es 705 .

b No se ofrece la posibilidad de abstención (como en los casos alemán y estadounidense). En España, en las elecciones de 1993 la tasa de participación fue del 77 por 100.

de las preferencias de voto, es el efecto dominante de la campaña (un 80,71 por 100 del total), mucho mayor en el caso de consistencia con las predisposiciones políticas $(77,87$ por 100$)$ que en el contrario (2,84 por 100). El efecto de activación, o de voto según las predisposiciones políticas, es mucho menor, aunque no despreciable (12,91 por 100) (el de reactivación es mínimo, un 0,99 por 100). El efecto de conversión, o de voto en contra de las predisposiciones políticas, es bastante menor (5,39 por 100), siendo la conversión tanto de los que tienen una intención de voto a un partido $(2,41$ por 100$)$ como de los que están indecisos antes de la campaña $(2,98$ por 100) similar.

La tabla 6 compara los efectos de la campaña electoral mostrados hace cincuenta años por Lazarsfeld, así como los encontrados recientemente para los casos americano y alemán, con los hallados en este trabajo para el caso español.

Tal y como se aprecia en la tabla, el reforzamiento fue el fenómeno más importante de las elecciones españolas, al igual que sucedió para las americanas de los años cuarenta y para las alemanas. Sólo en EE.UU. en los años ochenta la activación superó al refuerzo. La diferencia básica del caso español 
TABLA 6

Comparación de los efectos de la campaña electoral en varios estudios

\begin{tabular}{|c|c|c|c|}
\hline Estudios & Activación (\%) & Refuerzo (\%) & Conversión (\%) \\
\hline EE.UU. (Lazarsfeld, 1940) ${ }^{\mathrm{a}}$.................... & 17 & 53 & 8 \\
\hline EE.UU. (Finkel, 1980) ......................... & 46,6 & 39,8 & 13,3 \\
\hline Alemania (Finkel y Schrott, 1990) ........ & 5,8 & 80,6 & 13,6 \\
\hline 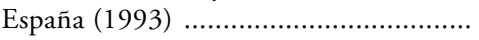 & 13,9 & 80,71 & 5,39 \\
\hline
\end{tabular}

NOTAS:

a Los porcentajes no suman el cien por cien porque Lazarsfeld analiza también el caso de abstención en el voto. Esta posibilidad no ha sido explorada en los otros estudios ni en el del caso español. Por lo tanto, estos porcentajes no son directamente comparables a los del resto de trabajos.

respecto del alemán se encuentra en que en el primer caso la activación fue un efecto de la campaña mucho más importante que la conversión (lo mismo sucedió, aunque en mayor medida, para el caso americano tanto en los años cuarenta como en los ochenta).

El que los fenómenos más importantes en el caso español sean, como hemos visto antes, el reforzamiento de aquellos consistentes con las predisposiciones políticas y la activación de los indecisos implica una predicción del voto antes de la campaña según las predisposiciones políticas máxima (los efectos de reforzamiento de los consistentes con las disposiciones, casilla $\mathrm{A}, \mathrm{y}$ de activación, casilla C, suman el 90,87 por 100 del total de los casos). En general, el porcentaje de casos predecibles antes de la campaña (efectos de refuerzo y activación) es el 93,71 por 100 (90,87 por 100 más el refuerzo de los inconsistentes con disposiciones políticas, casilla E). Si, como en la mayoría de los análisis realizados para predecir los resultados de la campaña electoral española de 1993, no se analizan las predisposiciones políticas, hay un efecto de incertidumbre sobre el resultado determinado por la existencia del grupo de los indecisos. Pero si se hubieran analizado las predisposiciones políticas de estos indecisos antes de la campaña el resultado no habría sido en absoluto incierto, dado el alto grado de predicción del modelo de activación política.

Sin embargo, lo que la anterior tabla 5 no revela son las diferencias entre los partidos. Estas diferencias están recogidas en la tabla 7.

Hay un mayor porcentaje de indecisos entre los predispuestos políticamente hacia el PSOE que hacia el PP. Además, un menor porcentaje de gente predispuesta políticamente hacia el PSOE tiene intención de votarle antes de la campaña que gente predispuesta hacia el PP tiene intención de votar a este partido. Sin embargo, un menor porcentaje de predispuestos hacia el PSOE tiene intención de votar al PP que predispuestos hacia este 


\section{TABLA 7}

Voto e intención de voto a PSOE y PP según la predisposición antes de la campaña

\begin{tabular}{|c|c|c|c|c|c|}
\hline \multirow[b]{2}{*}{ Predisposición antes de la campaña } & \multicolumn{2}{|c|}{ Voto } & \multicolumn{3}{|c|}{$\begin{array}{l}\text { Intención de voto } \\
\text { antes de la campaña }\end{array}$} \\
\hline & $P P$ & PSOE & $P P$ & PSOE & Indecisos \\
\hline 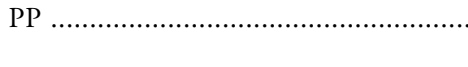 & $\begin{array}{c}88,71 \% \\
(275)\end{array}$ & $\begin{array}{c}11,29 \% \\
(35)\end{array}$ & $\begin{array}{c}81,72 \% \\
(219)\end{array}$ & $\begin{array}{c}4,85 \% \\
(13)\end{array}$ & $\begin{array}{c}13,43 \% \\
(36)\end{array}$ \\
\hline PSOE & $\begin{array}{c}10,28 \% \\
(52)\end{array}$ & $\begin{array}{l}89,72 \% \\
(454)\end{array}$ & $\begin{array}{c}3,2 \% \\
(14)\end{array}$ & $\begin{array}{c}79,41 \% \\
(347)\end{array}$ & $\begin{array}{c}17,39 \% \\
(76)\end{array}$ \\
\hline
\end{tabular}

NOTAS:

a En las casillas aparece el porcentaje por filas para el voto y para la intención de voto. Entre paréntesis se encuentra el número de casos correspondiente (el total es 816 para el voto y 705 para la intención de voto).

partido tienen intención de votar al PSOE. Con respecto al voto declarado después de la campaña ocurre algo similar. Lo que ha ocurrido, en definitiva, en la campaña del 93 en España es que había un porcentaje grande de indecisos en mayor medida predispuestos hacia el PSOE que al final le votaron, produciendo un cambio así en los resultados finales con respecto a la intención de voto.

Es interesante conocer si las personas predispuestas hacia un partido, predisposición que se ha hallado a partir de variables de antes de la campaña de 1993, votaron en las anteriores elecciones, las de 1989, a ese mismo partido. De igual forma es interesante ver si antes de las elecciones de 1993 se tiene intención de votar al mismo partido que se votó en las anteriores elecciones, o si al final se votó al mismo partido que se votó en 1989. Se introduce en el análisis de esta forma el recuerdo de voto de los individuos encuestados en 1989 , tal y como aparece en la tabla 8.

Las predisposiciones halladas antes de la campaña de 1993 coinciden fuertemente con el voto en 1989, más en el caso del PP que en el caso del PSOE. Esta diferencia entre los partidos es muy fuerte en el caso del porcentaje de personas que tienen intención de votar antes de la campaña de 1993 al partido por el que votaron en 1989: un porcentaje mayor de los que votó al PP en 1989 tiene intención de votarle en 1993 que de los que votaron al PSOE en las anteriores elecciones tiene intención de votarle en éstas. Los indecisos en 1993 suponen, además, un 7,95 por 100 de los que votaron al PP en 1989 y un 17,68 por 100 de los que votaron al PSOE. La diferencia es menor, aunque todavía existente, en el caso del porcentaje de gente que votó al mismo partido que en 1989. 


\section{TABLA 8}

Voto en 1989 según predisposición, voto e intención de voto en 1993

\begin{tabular}{|c|c|c|c|c|}
\hline Partido & $\begin{array}{c}\text { Voto en } \\
1989(\%)^{a}\end{array}$ & $\begin{array}{c}\text { Porcentaje que tiene } \\
\text { predisposición } \\
\text { en } 1993 \text { hacia } \\
\text { el partido por el } \\
\text { que votó en } 1989\end{array}$ & $\begin{array}{c}\text { Porcentaje } \\
\text { que tiene intención } \\
\text { de votar antes } \\
\text { de la campaña } \\
\text { de } 1993 \text { al partido } \\
\text { que votó en } 1989^{\mathrm{b}}\end{array}$ & $\begin{array}{l}\text { Porcentaje que vota } \\
\text { en } 1993 \text { al partido } \\
\text { que votó en } 1989\end{array}$ \\
\hline PP & $\begin{array}{l}24,09 \\
(186)\end{array}$ & $\begin{array}{l}96,34 \\
(158)\end{array}$ & $\begin{array}{l}91,48 \\
(161)\end{array}$ & $\begin{array}{l}97,56 \\
(160)\end{array}$ \\
\hline PSOE ............... & $\begin{array}{l}75,91 \\
(586)\end{array}$ & $\begin{array}{l}90,16 \\
(394)\end{array}$ & $\begin{array}{l}75,44 \\
(384)\end{array}$ & $\begin{array}{l}89,47 \\
(391)\end{array}$ \\
\hline
\end{tabular}

NOTAS:

a Debajo del porcentaje aparece entre paréntesis el número de casos (los totales son 772 para el voto en 1989, 601 para la predisposición y el voto en 1993, y 685 para la intención de voto en 1993).

b Los indecisos suponen un 7,95 por 100 de los que votaron al PP en 1989, y un 17,68 por 100 de los que votaron al PSOE en 1989.

\section{LOS INDECISOS COMO GRUPO CLAVE DE LAS ELECCIONES ESPAÑOLAS DE 1993}

A lo largo del trabajo se ha ido poniendo en evidencia la tesis de que los indecisos fueron un grupo clave en los resultados de las elecciones de 1993. De una manera intuitiva, en medios académicos y periodísticos se ha aludido frecuentemente a esta tesis. Suele decirse que los indecisos tendieron a votar al PSOE, y que éste consiguió movilizar a «sus votantes». Durante las elecciones de 1993, el PSOE, consciente de la necesidad de movilizar a su electorado indeciso, hizo hincapié en que la gente votara; sabía que el electorado del PP estaba ya movilizado, pero no el suyo (Sinova, 1993: 106; Arango y Díez, 1993: 14$)^{38}$.

Esta tesis se ha venido reforzando a lo largo de todo el trabajo. Los indecisos votaron en mucha mayor medida al PSOE que al PP, más los que dudaban antes de la campaña si votar o no que los que dudaban a qué partido votar (un 64,52 por 100 contra un 62,96 por 100 ). Además, había más votantes del PSOE en 1989 que estaban indecisos en 1993 que los correspondientes del PP. Había un mayor porcentaje de indecisos con predisposición política hacia el

${ }^{38}$ Un ejemplo muy ilustrativo de llamada a la participación se da en una carta que González mandó a todo el electorado. La carta dice así: «El próximo día 6 de junio usted tiene en sus manos una importante decisión ante la que no cabe la indiferencia o el desinterés» (Sinova, 1993: 110). 
PSOE que hacia el PP, más los indecisos sobre si votar o no que los que dudaban entre a qué partido votar (un 70,97 por 100 contra un 66,67 por 100). La tabla 5 ha mostrado que la activación de los indecisos, el que éstos finalmente votaran por el partido al que estaban predispuestos inicialmente, fue un fenómeno muy importante en las elecciones de $1993^{39}$. Finalmente, introduciendo la consistencia o la inconsistencia de los votantes indecisos, obtenemos la tabla 9 .

\section{TABLA 9}

Voto al PSOE y al PP de los indecisos consistentes e inconsistentes

\begin{tabular}{|c|c|c|}
\hline Voto $(\text { julio })^{\mathrm{a}}$ & Indecisos consistentes ${ }^{\mathrm{b}}$ & Indecisos inconsistentes \\
\hline \multicolumn{3}{|l|}{ PP } \\
\hline Porcentaje fila .............................. & 68,29 & 31,71 \\
\hline Porcentaje columna ...................... & 30,77 & 61,9 \\
\hline Número de casos ............................ & $(28)$ & $(13)$ \\
\hline \multicolumn{3}{|l|}{ PSOE } \\
\hline Porcentaje fila ............................. & 88,73 & 11,27 \\
\hline Porcentaje columna .................... & 69,23 & 38,1 \\
\hline 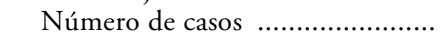 & $(63)$ & $(8)$ \\
\hline
\end{tabular}

NOTAS:

a El total de casos es 112 .

b Si se desagrega en indecisos sobre a qué partido votar y sobre si votar o no, salen unas cifras parecidas. El 70 por 100 de indecisos sobre el partido al que votar de los que votan al PP lo hacen consistentemente, y el 63,64 por 100 de los indecisos sobre si votar o no. Para el PSOE estas cifras son el 88,24 y el 90 por 100 .

Un mayor porcentaje de votantes del PSOE que del PP son indecisos consistentes, es decir, que al final votan al partido al que estaban inicialmente predispuestos. Para el PSOE, el 90 por 100 de los indecisos sobre a qué partido votar estaban indecisos y votan consistentemente, mientras que el 88,24 por 100 de los indecisos lo hacen sobre si votar o no ${ }^{40}$.

Por lo tanto, parece que el éxito del PSOE en las elecciones generales de 1993 puede explicarse en cierta medida por la activación de las predisposiciones políticas de los indecisos hacia este partido (y/o que le habían votado en 1989). Además, parece también que, aunque las diferencias no son muy claras, los que dudaban si votar o no antes de las elecciones tienen un mayor peso en

39 Aunque más entre los que dudaban a qué partido votar (81,48 por 100) que los que no sabían si votar o no $(80,65$ por 100$)$.

${ }_{40}$ Para el PP ocurre al revés y la diferencia es mayor, un 63,64 vs. un 70 por 100. 
el electorado del PSOE que los indecisos sobre a qué partido votar. Así pues, la cuarta y última hipótesis queda probada: el PSOE logró movilizar a «sus» votantes, tanto a aquellos que se encontraban reacios hacia votar otra vez al PSOE como, en mayor medida, a los que no pensaban votar.

\section{CONCLUSIONES}

En este trabajo he pretendido replicar los análisis pioneros de Lazarsfeld y su grupo de Columbia y dos estudios recientes llevados a cabo en Estados Unidos y Alemania, para analizar los efectos de la campaña electoral española de 1993. Las predisposiciones políticas que los individuos presentan al comenzar la campaña electoral son una pieza clave de los análisis de Lazarsfeld y su equipo, aunque han sido olvidadas en los posteriores estudios sobre los efectos de la campaña electoral en el voto. Para el caso español, la escasez de estudios empíricos sobre los efectos de la campaña electoral y el olvido del análisis de las predisposiciones políticas antes de la campaña justifican el trabajo aquí realizado. Este estudio ha sido posible gracias a la existencia de datos adecuados, al tratarse de una encuesta de panel aplicada antes y después de la campaña.

Los resultados obtenidos son, en resumen, los siguientes. Las predisposiciones políticas que los individuos presentan al comenzar la campaña electoral predicen con bastante precisión el voto que finalmente emiten. Para el caso español, estas predisposiciones están configuradas por la identificación partidista, la ideología, la valoración de los candidatos y la educación. Sin embargo, el efecto de la campaña electoral, que afecta a ciertas actitudes políticas, aunque pequeño, no es despreciable, sobre todo en comparación con el caso americano. Si bien las actitudes políticas cambian durante la campaña en el sentido predicho por las predisposiciones políticas anteriores, la impredictabilidad que se deriva de la campaña (es decir, los cambios en un sentido diferente al predicho) en el español es mayor que en otros casos. Es evidente, sin embargo, que la exposición a determinados medios de comunicación afecta poco estos cambios en las actitudes supuestamente producidos por la campaña electoral. Teniendo en cuenta, además de las predisposiciones políticas y el voto de los individuos, su intención de voto antes de la campaña electoral, puede profundizarse en los efectos específicos de la campaña implícitos en la obra de Lazarsfeld. Los efectos más importantes que se produjeron en la campaña electoral de 1993 fueron el reforzamiento de los que tenían unas preferencias de voto consistentes con las predisposiciones políticas y la activación de los indecisos. Este último efecto fue el determinante de los resultados electorales de entonces.

Durante la campaña electoral, el PSOE aumentó su voto agregado más que el PP, respecto a la intención de voto antes de la campaña. Su efecto de reforzamiento fue mayor, aunque el de conversión fue menor. Sin embargo, este último efecto fue mínimo para la campaña electoral de 1993. El efecto más importante de cara a la explicación del triunfo del PSOE, en cierta medida 
inesperado (sobre todo por su magnitud), fue la activación de los indecisos predispuestos políticamente hacia este partido o que le habían votado en anteriores elecciones. Este grupo finalmente votó al PSOE. El PSOE logró, en mucha mayor medida que el PP, recuperar a sus votantes que o bien tenían intención de votar a otro partido o bien, y en una mayor proporción, pensaban abstenerse. Posiblemente, los mensajes que utilizó el PSOE en su campaña en contra del abstencionismo, junto con la sensación de la opinión pública de verdadera incertidumbre en el resultado, hicieron que sobre todo ese sector indeciso del PSOE se movilizara y activara según sus predisposiciones políticas, y que votara finalmente al PSOE. Las causas específicas de este cambio quedan fuera del alcance de este trabajo ${ }^{41}$.

Aunque la activación de los indecisos es completamente predecible para el modelo de activación política, en los sondeos preelectorales este fenómeno no se tiene en cuenta al no analizar las predisposiciones políticas de estos indecisos, lo que en muchos casos lleva a la sorpresa por los resultados. Un mecanismo similar parece haber tenido lugar en las siguientes elecciones generales de 1996. Los sondeos electorales de antes de la campaña y durante la campaña daban al PP una victoria muy por encima del PSOE, incluso se pronosticaba la mayoría absoluta del primer partido. Pero los resultados fueron una leve victoria del PP sobre el PSOE. Aunque sólo el análisis de los datos permitiría corroborar la hipótesis de la activación política, parece a priori que han podido actuar mecanismos semejantes.

\section{APÉNDICE ESTADÍSTICO}

\section{Prueba Chi de bondad de ajuste para el modelo de la tabla 1}

La prueba de bondad de ajuste $\mathrm{Chi}^{2}$ para el modelo completo de activación política presenta un problema a la hora de realizarse. El número de patrones de covarianza con el que opera (808) se aproxima mucho al número de observaciones de la estimación (816), con lo que el test $\mathrm{Chi}^{2}$ no es fiable (da $\left.\mathrm{p}>\mathrm{chi}^{2}=0,9523\right)$. Si los patrones de covarianza se reducen a 10 grupos se sigue superando este test $\left(\mathrm{p}>\mathrm{chi}^{2}=0,1287\right)$, con lo que se puede decir que estamos ante un modelo bien ajustado.

${ }^{41}$ Ver, además del artículo ya citado de Barreiro y Sánchez-Cuenca (1998), en el que se destacan factores como el liderazgo, la ideología y las redes sociales, el trabajo de Morillas (1998), en el que se apunta el argumento de que el aumento de las expectativas de éxito del PP hizo que los indecisos votaran al PSOE. 


\section{Prueba Chi² de bondad de ajuste para el modelo de la tabla 2}

Cuando se realizó la prueba de bondad de ajuste $\mathrm{Chi}^{2}$ para el modelo de activación política sin cambios durante la campaña con todos los casos del modelo, ésta no se superaba (la $\mathrm{p}>\mathrm{chi}^{2}$ era 0 ). Se hizo un análisis de residuos y se vio que había un caso que tenía un residuo de $-18,9427$ (el residuo del siguiente caso en orden decreciente según el tamaño de los residuos era de -6,7213; el mayor residuo era casi tres veces el segundo mayor residuo). Se intentó localizar al caso, era la observación número 937. Se trataba de una persona que está bastante identificada con el PSOE (IDP Mayo=2), de extrema izquierda (IDEO Mayo=5), que valora mucho a Felipe González sobre Aznar $(\mathrm{CAND} M a y o=7)$, que posee una educación bastante baja $(\mathrm{EDU}=3)$, pero que, paradójicamente, vota al $\mathrm{PP}(\mathrm{VOTO}=0)$. Es un individuo que presenta un perfil, o en nuestra jerga unas predisposiciones políticas, pro-PSOE casi perfecto pero que, sin embargo, vota al PP. Si lo eliminamos de la regresión y hacemos otra vez la prueba de bondad de ajuste $\mathrm{Chi}^{2}$ sale esta vez no significativa, esto es, se pasa la prueba $\left(\mathrm{p}>\mathrm{chi}^{2}=0,6229\right)$. El $\mathrm{R}^{2}$ de la nueva regresión sin la observación 937 sube, aunque ligeramente $(0,5966)$, y los coeficientes cambian muy marginalmente; por ello en los resultados que se han mostrado en la tabla 2 y en los análisis siguientes no se ha quitado esta observación, ya que no los distorsiona mucho.

\section{Problema de heteroscedasticidad en la predicción de la ideología en julio de la tabla 3}

Se hicieron regresiones con cada variable independiente por separado y en los dos casos se encontraron problemas de heteroscedasticidad. Se quitaron los casos missing del valor cero de la variable dependiente, forma en la que en un principio se había operacionalizado esta variable. Aun así seguía habiendo problemas de heteroscedasticidad. Se analizaron las desviaciones típicas de la variable dependiente para cada variable independiente ${ }^{42}$. En el caso de la ideología antes de la campaña, se aprecia una ligera tendencia decreciente no continua que supone que para ideologías de derechas antes de la campaña la variación de la ideología es mayor después de la campaña que para ideologías de izquierdas. Para el caso de la diferencia en la valoración de los candidatos antes de la campaña, la tendencia decreciente es tan ligera que no se puede afirmar nada. No parece, pues, que los problemas de heteroscedasticidad del modelo puedan ser atribuidos a la diferencia de valoración de los candidatos antes de la campaña, aunque sí a la ideología antes de la campaña. Las desviaciones típicas de la variable dependiente para cada valor de cada variable independiente (ordenadas de menor a mayor) son las siguientes:

${ }^{42}$ Los gráficos no se han mostrado aquí. 
- Ideología antes de la campaña: 2,4516;2,8856; 2,1424; 1,9683; 1,$8921 ; 2,0744 ; 1,8908 ; 1,4723 ; 1,6535 ; 1,6601 ; 1,8551$.

- Diferencia en la valoración de los candidatos antes de la campaña: 2,$1988 ; 2,7487 ; 2,2563 ; 2,0212 ; 2,1498 ; 2,5895 ; 2,0599 ; 2,7117$; 1,$9316 ; 2,298 ; 2,3548 ; 2,1994 ; 2,0397 ; 1,5112 ; 1,788 ; 1,9425$; 1,$583 ; 1,7795 ; 1,5695 ; 1,8116 ; 2,0197$.

También se hicieron pruebas de residuos. Primero se realizó un gráfico con los residuos según los valores predichos por el modelo. El gráfico revelaba una tendencia decreciente clara. Esto quiere decir que los residuos son menores según los valores predichos por el modelo, la ideología después de la campaña, aumenten. También se realizaron gráficos de los residuos contra los valores de ambas variables independientes. Para la ideología antes de la campaña sí que existe una ligera pauta descendente, que casi no se encuentra en el caso de la diferencia en la valoración de los candidatos. Esto quiere decir que a medida que la ideología antes de la campaña está más a la izquierda, los residuos del modelo disminuyen. Por lo tanto, el problema se encontrará fundamentalmente en la variable dependiente y, si acaso, en la ideología antes de la campaña.

\section{REFERENCIAS}

Arango, Joaquín, y DíEz, Miguel (1993): «6-J: El sentido de una elección», Claves, 36: 10-18.

Barreiro, Belén, y SÁnCHEZ-CuenCA, Ignacio (1998): "Análisis del cambio de voto hacia el PSOE en las elecciones de 1993", REIS, 82: 191-211.

Biorcio, Roberto, y MAnnheimer, Renato (1995): «Relationships Between Citizens and Political Parties», en Hans-Dieter Klingemann y Dieter Fuchs (eds.), Citizens and the State, Oxford: Oxford University Press, pp. 206-226.

Del Castillo, Pilar (1990): "Aproximación al estudio de la identificación partidista en España», Revista de Estudios Politicos, 70: 125-141.

Díez Nicolás, Juan, y SemetKo, Holli A. (1995): «La televisión y las elecciones de 1993», en Alejandro Muñoz-Alonso y Juan Ignacio Rospir (eds.), Comunicación Política, Madrid: Universitas, pp. 243-304.

El País (1996): «González dice que hará una oposición razonable», lunes 4 de marzo, p. 24.

FINKEL, Steven E. (1993): "Reexamining the "Minimal Effects" Model in Recent Presidential Campaigns", The Journal of Politics, 55, 1: 1-21.

Finkel, Steven E., y SchrotT, Peter R. (1995): "Campaign Effects on Voter Choice in the German Election of 1990", British Journal of Political Science, 25, 3: 349-378.

GONZÁLEZ, Juan Jesús (1993): «Clase y apoyo electoral», Sistema, 112: 41-71.

González Álvarez, Pablo (1998): "Clase, voto y Estado del Bienestar en España (1986-1996)», manuscrito, Instituto Juan March (CEACS), Madrid.

Gunther, Richard, Montero, José Ramón, y Wert, José Ignacio (1999): «The Media and Politics in Spain: From Dictatorship to Democracy», en Richard Gunther y Anthony Mughan (eds.), Democracy and the Media: A comparative perspective, Cambridge y New York: Cambridge University Press.

Justel, Manuel (1992): «El líder como factor de decisión y explicación del voto», Institut de Ciènces Polítiques i Socials, WP núm. 51, Barcelona. 
Lancaster, Thomas D., y Lewis-Beck, Michael S. (1986): «The Spanish Voter: Tradition, Economics, Ideology», The Journal of Politics, 48: 648-674.

Lazarsfeld, Paul F., et al. [1944] (1968): The People's Choice, 3.a ed., New York: Columbia University Press.

Maravall, José María, y PrZeWorski, Adam (1998): «Political Reactions to the Economy: The Spanish Experience», Instituto Juan March (CEACS), WP núm. 127, Madrid.

MONTERO, José Ramón (1993): «Las dimensiones de la secularización: Religiosidad y preferencias políticas en España», en Rafael Díaz-Salazar y Salvador Giner (eds.), Religión y sociedad en España, Madrid: CIS, pp. 175-242.

Montero, José Ramón, y GunTer, Richard (1994): «Los anclajes del partidismo: Un análisis comparado del comportamiento electoral en cuatro democracias del sur de Europa», en Pilar del Castillo (ed.), Comportamiento político y electoral, Madrid: CIS, pp. 467-548.

MORILlLAS, Rafael (1998): «Votar cambiando la intención», manuscrito, Instituto Juan March (CEACS), Madrid.

Schmitt, Hermann, y Holmberg, Sören (1995): «Political Parties in Decline?», en Hans-Dieter Klingemann y Dieter Fuchs (eds.), Citizens and the State, Oxford: Oxford University Press, pp. 95-133.

SINOVA, Justino (1993): Un millón de votos, Madrid: Ediciones Temas de Hoy.

\begin{abstract}
This paper looks into the effects that the 1993 election campaign in Spain had on the conduct of the electorate, and follows the old assumptions used by Lazarsfeld and his Columbia group, as well as those used by his successors. A panel data survey was used for this, as were the measurements taken before and after the elections. There were two main targets. Firstly, and using the activation model, to examine whether the individual vote was influenced by the election campaign or whether it had already been decided beforehand by political inclinations held before the campaign began and was stimulated during the campaign itself. Secondly, to analyse the specific effects the campaign had on voting decisions (activation, reinforcement and conversion), besides an interpretation of why undecided voters were undecided, and what may have changed their minds to move in the direction of the PSOE (the Spanish Socialist Party). This article demonstrates that the conclusions reached by the work done by Lazarsfeld and his team are certainly true in the case of Spain: the political tendencies shown by all individuals when electoral campaigns begin are able to predict, to a large extent, what their final vote will be. As a result, the effect of the electoral campaign is limited. The specific effects of the electoral campaign carried out in 1993 are as follows: the influence of those who had voting preferences which were in line with political predisposition was reinforced, and those who were undecided were forced into making a decision (activation).
\end{abstract}

